\title{
Study of Mechanical Behaviour \& Water-Absorption Characteristics of Sisal-Bagasse Fibre Reinforced Hybrid Epoxy Composites
}

\author{
Prashant Dwivedi, Saurabh Kumar Shukla, Anurag Srivastava
}

\begin{abstract}
The aim of this research work is to perform an experimental analysis of mechanical properties and water absorption characteristics of sisal-bagasse fibre reinforced hybrid epoxy composites. In this article, sisal and bagasse fibres have been reinforced into epoxy resin in different fibre ratios keeping the composite resin and fibre ratio constant i.e. 60:40. In order to achieve the objectives, five different composites were prepared by reinforcing sisal and bagasse fibres in varying weight compositions in the composite. After preparation of samples different test were performed for testing of their mechanical performance (i.e. Tensile test, Impact test, Rockwell Hardness, Flexural test test) and water absorbing capacity of the fibres. The influence of alkali treatment (with 5 wt. \% $\mathrm{NaOH}$ solution for $10 \mathrm{Hrs}$.) on mechanical properties of sisal and bagasse reinforced hybrid composites was also investigated.

After detailed analysis of results obtained it was concluded that as the amount of sisal fibre increased in the sisal/bagasse hybrid composite increased its tensile strength, tensile modulus and hardness increased and upon introduction of bagasse fibre its flexural strength, flexural modulus and water absorbing capacity increased. Impact Strength is maximum for alkali treated composite having composition in the ratio of $60: 20: 20$ and it increases by $\mathbf{7 3 . 1 7 \%}$ compared to neat epoxy. Tensile and Flexural Modulus of composite (Untreated) with weight ratio as 60:20:20 increased by $18.79 \%$ and $54.89 \%$ respectively compared to neat epoxy. Tensile and Flexural Strength is maximum for neat epoxy composite and it also shows least water absorbing capacity due to absence of fibres.
\end{abstract}

Index Terms - Sisal, Bagasse, Epoxy, Reinforcement.

\section{INTRODUCTION}

\section{A. INTRODUCTION TO COMPOSITES}

A composite comprises of two major elements in which one of the elements, called as the reinforcing phase, in the shape of sheets, fibers or particles is embedded into the other element called the matrix phase. Composites normally have a fiber or particle phase that is stiffer and tough than the continuous matrix phase [1]. The properties of resultant material i.e. composite are better than the properties of the individual materials that make the composite.

The matrix works as a medium of load transfer between fibers whereas reinforcement provides strength and stiffness to the matrix. The matrix even protects the fibers from environmental damage during and after processing of

Prashant Dwivedi, PG Research Scholar, Department of Mechanical Engineering, SRIMT, Lucknow, India, 7408926463

Saurabh Kumar Shukla, Assistant Professor, Department of Mechanical Engineering, SRIMT, Lucknow, India, 9458480892

Anurag Srivastava, Head of Department, Department of Mechanical Engineering, SRIMT, Lucknow, India, 9793000023 composite. Composites are not only employed for their structural applications but also for their electrical, thermal, environmental and tribological applications.

\section{B. DEFINITION OF COMPOSITES}

The following definition gives a encompassing view regarding composites:

Beghezan[2] defines as "Composites are the compound materials that are differentiated from alloys because their individual constituents retain their characteristics."

Van Suchetclan[3] defines composite as heterogeneous materials which consists of more than two solid phases, in close contact with each other on a microscopic scale.

Jartiz[4] said that "Composites are those multi utility material systems that provide attributes which are unobtainable from any other material. They are made physically by combining two or more than two compatible materials which are different in composition, characteristics and form".

Kelly[5] clearly stressed that composites must not only be regarded simply as a combination of two materials. Instead in broader perspective; the composite has its own separate properties.

\section{COMPONENTS OF COMPOSITE}

The composite material primarily comprises of two elements:

- Reinforcement

- Matrix

a) REINFORCEMENT- The reinforcement generally provides strength to the composite and appends its mechanical properties. It is generally found in fibrous or particle form and also provides stiffness to the composites. The purpose of the reinforcement in a composite is primarily of appending the mechanical properties of the neat resin system. For majority of applications, the fibers are organized into some form of sheet, identified as fabric, for proper handling. Different ways of assembling fibers into sheets and the diversity of fiber orientation helps the reinforcement to obtain different characteristics.

b) MATRIX- The matrix component generally comprises the major part of a composite. Materials in fibrous form resemble good mechanical properties and for achievement of these properties the fibres must be bonded by a matrix. Matrix can be of three material types - Polymer, metals or ceramics. 
The matrix sets apart the fibres from one another and holds the fibres in position. The matrix must hold ability to deform without difficulty under applied load, distribute the load onto the fibres and also spread the stress concentration evenly.

\begin{tabular}{|c|c|c|c|c|c|}
\hline $\begin{array}{l}\text { Seed } \\
\text { fibre } \\
\text { Cotton }\end{array}$ & $\begin{array}{l}\text { Bast } \\
\text { fibre } \\
\text { Jute }\end{array}$ & $\begin{array}{l}\text { Leaf fibre } \\
\text { Sisal }\end{array}$ & $\begin{array}{l}\text { Stalk } \\
\text { fibre } \\
\text { Bamboo }\end{array}$ & $\begin{array}{l}\text { Wood } \\
\text { fibre } \\
\text { Maple }\end{array}$ & $\begin{array}{l}\text { Fruit } \\
\text { fibre } \\
\text { Coconut }\end{array}$ \\
\hline Kapok & Fax & Banana & Wheat & Pine & Betel nut \\
\hline \multirow[t]{3}{*}{ Alfafa } & Hemp & Date palm & Rice & Spruce & \\
\hline & Ramie & $\begin{array}{l}\text { Pineapple } \\
\text { leaf }\end{array}$ & Barley & Cedar & \\
\hline & Kenaf & Abaca & Corn & Deodar & \\
\hline
\end{tabular}

\section{CLASSIFICATION OF COMPOSITES}

Composites can be identified in two ways:

1. According to the type of matrix involved

2. According to the reinforcement type

a) ACCORDING TO THE TYPE OF MATRIX INVOLVED: There are basically three categories of composites depending on the type of matrix involved:

1. Polymer Matrix Composites

2. Metal Matrix Composites

3. Ceramic Matrix Composites

b) ACCORDING TO THE TYPE OF REINFORCEMENT: There are basically three types of composites based on the type of reinforcement used[6]:

a) Particulate Reinforced Composites

b) Fibre Reinforced Composites

c) Flake Reinforced Composites
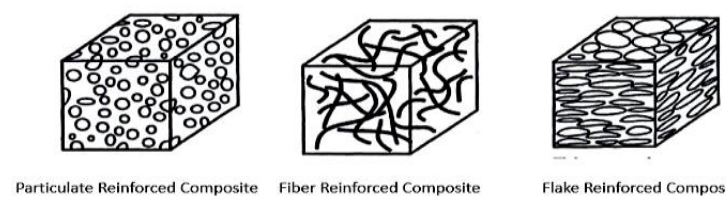

Flake Reinforced Composite

\section{E. HYBRID COMPOSITES}

The composites that involve the reinforcement of two or more fibres in a common matrix are called hybrid composites. Hybrid composites are specifically employed in those conditions which require a combination of different set of properties of different fibres or when both lateral and longitudinal mechanical performance of composite is required. Hybrid Composites provide us with the advantage of using the properties of one fibre to compliment that is deficient in the other. The properties of the hybrid composites depends upon many factors which are- fiber density, fibre length, fibre quality, fibre orientation, nature of interface between fibres, fibre to matrix bonding capacity etc.

\section{F. NATURAL FIBRE REINFORCED COMPOSITES}

Over the last few years, natural fibres have drawn the attention of many scholars and industries such as automobile, aviation, etc. to be used as a reinforcement in polymer composites because of environmental concerns. A lot of plastic waste is still to be disposed a matter of great concern globally. We are adding million tons of plastics in our oceans and landfills every year whose disposal has now became a global challenge. Hence scientist and researchers have to find out some material that is light weight, biodegradable, easily accessible and of low cost and all the criteria are fulfilled by natural fibres. Hence it has became a matter of great interest for the industries.

The Natural Fibre Composites( NFCs) are environment friendly, hence widely used in automobile and aerospace industries, building and construction industries, military and defense organizations, products and packaging companies, etc.

\section{G. NATURAL FIBRES}

Fibers can be of two types: - natural and man-made or synthetic. Natural fibres refers to the fibers obtained from natural sources i.e. such as jute, sisal, sugarcane stalks, wheat/paddy leftovers, hemp, sisal, ramie, bamboo, flax, banana, cotton, pineapple leaf fibre, etc. whereas synthetic fibres involve glass, carbon, aramid, etc.

Unlike other synthetic or man-made fibres natural fibres are light weight, low density, good specific properties, low cost, non-abrasive, biodegradable and readily available but also some negative traits such as hydrophilic behavior, poor interfacial adhesion and their properties may also vary with time. According to the sources of origin natural fibre can be broadly classified into following categories[7]:

a) Plant fibres

b) Animal fibres

c) Mineral fibres

\section{Classification of Plant fibres on the basis of source of origin}

\begin{tabular}{ccccc}
\multicolumn{5}{c}{ Chemical compositions of some natural fibres } \\
$\begin{array}{c}\text { Natural } \\
\text { Fibres }\end{array}$ & $\begin{array}{c}\text { Cellulos } \\
\text { e }\end{array}$ & $\begin{array}{c}\text { Hemi } \\
\text { cellulose }\end{array}$ & Lignin & Pectin \\
Flax & 71 & $18.6-20.6$ & 2.2 & 2.3 \\
Kenaf & $31-57$ & 20.3 & $15-19$ & - \\
Sisal & $47-78$ & $10-24$ & $7-11$ & $10-12$ \\
Ramie & $68.6-91$ & $5-16.7$ & $0.6-0.7$ & 1.9 \\
Henquen & 77.6 & $4-8$ & 13.1 & - \\
Jute & $45-71.5$ & $13.6-21$ & $12-26$ & 0.2 \\
Bagasse & $45-55.2$ & 16.8 & 25.3 & $0.6-0.8$ \\
Abaca & $56-63$ & $15-17$ & $7-9$ & - \\
Oil Palm & 65 & - & 29 & - \\
Bamboo & $26-43$ & 30 & $21-31$ & $8-10$ \\
Hemp & $57-77$ & $14-22.4$ & $3.7-13$ & 0.9 \\
Coir & $32-43$ & $0.15-0.25$ & $40-45$ & $10-15$
\end{tabular}

\section{H. ADVANTAGES OF NATURAL FIBRE COMPOSITES}

The various advantages of natural fibre composites are:

a) Renewable source, readily available, biodegradable.

b) Low specific weight, high specific strength and stiffness than synthetic composites. 
c) Production cost and energy requirement is low than that of synthetic composite.

\section{DISADVANTAGES OF NATURAL FIBRE COMPOSITES}

The several disadvantages of natural fibre composites are:

a) Low durability and less consistency in properties as compared to synthetic composites.

b) Poor moisture and fire resistance.

c) Low impact strength and anisotropic behavior.

d) Hydrophilic behavior i.e. to absorb moisture makes them difficult to be employed in wet conditions.

e) Restriction to maximum processing temperature and sometimes poor fibre/matrix adhesion makes it difficult for fabrication of composites.

\section{J. APPLICATIONS OF NATURAL FIBRE COMPOSITES}

The application areas of natural fibre composites are:

a) In Electrical industry and for manufacture of storage devices.

b) In manufacturing of daily use products such as helmets, lamp shades etc.

c) In automobile, aviation, packaging, paper and pulp industries, etc.

d) In manufacturing of hulls of boats, seats and cabins in railway coaches

e) In manufacture of door panels and dashboard of car by luxury car companies such as BMW, Mercedes, Audi etc.

\section{LITERATURE REVIEW}

\section{A. RECENT PROGRESS IN SISAL AND BAGASSE BASED COMPOSITES}

This chapter gives a deep insight on the previous work that has provided the base for this research work. Various research papers published in last 20 years have been reviewed for accomplishment of the current research work out of which some are discussed below:

* Sangamesh Edway et al 2016[8] investigated for mechanical properties i.e. tensile and flexural strength on Sisal/Hemp reinforced epoxy composite with the amount of reinforcement varying from $10 \%$ to $40 \%$ in the composite. The fibres were also alkali treated in $10 \% \mathrm{NaOH}$ solution for 10 hours which resulted in improvement of properties. The composites fabricated by compression moulding technique at room temperature showed an uplift in tensile and flexural strength at $30 \%$ sisal and hemp fibre with Shore- D hardness number increasing with increasing fibre percentage.

* KV Sreenivasa Rao et al 2016[9] investigated the mechanical properties and water absorbing behavior of $\mathrm{NaOH}$ treated sisal and coir reinforced hybrid epoxy thermoset composite with amount of reinforcement varying from 10 to $50 \%$ and prepared by cold pressing method. Epoxy resin AW 106 and hardener HV 953 was used for matrix preparation. It was found that amount of water absorption increased with increasing fibre content. Tensile strength and flexural strength were maximum for $40 \%$ Sisal/Coir composite with values being $48.2 \mathrm{MPa}$ and 76.68 $\mathrm{MPa}$ respectively.

* P.C. Gope et al 2011[10] developed the Bagasse/Glass reinforced composite with bagasse content varying from 15 to $30 \%$ keeping glass fibre constant at $5 \%$. It was found that impregnation of bagasse fibre improved the modulus of elasticity, water absorption capacity and impact strength of the composite but decreased the ultimate tensile strength and bending strength.

* R. Prasanna Venkatesh et al 2015[11] studied the mechanical properties of Sisal/Bamboo reinforced hybrid polyester composites with fibre lengths varying in 5,10 and $15 \mathrm{~cm}$ and their weight varying in 10,15 and $20 \%$. The fibres were also alkali treated with $10 \% \mathrm{NaOH}$ for 24 hours which showed an increase in all mechanical properties and decrease in water absorbing tendency of fibres when compared with untreated one. This work resulted in $30 \%$ increase in tensile strength, $27.4 \%$ in flexural strength and $36.9 \%$ in impact strength with maximum properties at $20 \%$ fibre content.

* DS Kumar et al 2017[12] studied the development and characterization of hybrid bagasse epoxy composites prepared by reinforcing bagasse fibre in pure epoxy in 1 to $4 \%$ by weight. Epoxy resin AW 106 was mixed with hardener HV 953 to prepare composite. The work showed an improvement in mechanical properties with 3 $\mathrm{wt} \%$ bagasse epoxy composite showing highest tensile strength and decreased down when increased to $4 \mathrm{wt} \%$ due to localized stress but hardness increased with increase in bagasse content.

* Jai Inder Preet Singh et al 2017[13] studied the effect of alkali treatment on five different natural fibres ( jute, banana, sisal, hemp and abaca) by treating them with $5 \%$ (w/v) $\mathrm{NaOH}$ solution for 1 hour at $40^{\circ} \mathrm{C}$. Then all treated and untreated fibres were reinforced into neat epoxy resin AW 106 with hardener HV 953 in ratio 10:8 by weight and fibre: resin ratio being 40:60. It was found that treated jute composite had maximum tensile strength of $431 \mathrm{MPa}$ and flexural strength was maximum for hemp fibre epoxy composite.

* Abdul Nazeer et al 2014[14] examined the mechanical properties of Coir epoxy composite samples with varying coir fibre lengths $(5,10,15 \mathrm{~mm})$ after alkali treatment of fibres with $5 \% \mathrm{NaOH}$ treatment for 24 hours. Epoxy resin AW 106 was used along with hardener HV 953 for preparation of composites using hand layup technique. The results showed improvement in mechanical properties upon treatment with maximum tensile strength for $15 \mathrm{~mm}$ fibre length.

* RG Padmanabhan et al 2015[15] used alovera and bagasse fibre to develop a new class of composite with epoxy resin as matrix with varying ratio between fibres and matrix followed by alkaline treatment of fibres. Various mechanical tests were also performed on these developed composites with $35 \%$ vol. of fibres showing maximum tensile strength and and $25 \%$ volume showing maximum flexural strength.

* Anurag Thawait et al 2016[16] utilized Musa acuminata, locally known as Banana fibre along with AW 106/HV 953 resin to prepare composites by hand layup 
technique. The fibres were dried, cut in lengths of 10, 15 and $20 \mathrm{~mm}$ then fabricated in mould, pressed by $50 \mathrm{~kg}$ weight for 24 hours. The results showed an increase in water absorption and tensile strength with maximum at $15 \%$ by mass and impact energy maximum at $20 \%$ by mass.

* M. Sudhagar et al 2016[17] studied the mechanical properties of hybrid glass-sisal-flax fibres reinforced in Epoxy resin AW 106/HV 953 mixed in 1:1 by volume. Samples were produced in resin: fibre ratio of $60: 40$ by hand layup technique. The fibres were also treated with $10 \% \mathrm{NaOH}$ solution and cut in different lengths of 20 , 40, 60 and $80 \mathrm{~mm}$. After 24 hours samples were cut for testing which showed an increase in mechanical properties of resin .

* P. Sudhir Kumar et al 2017[18] used tamarind and date palm seed powder as reinforcement in epoxy AW 106 resin along with hardener HV 953 for composite preparation. The resin and hardener were mixed in 1:1 ratio by volume to prepare matrix and seeds were grinded and mixed into matrix and moulded. After fabrication certain tests were performed on samples which resulted in improvement of properties upon reinforcement.

* Amit Kumar Tanwer et al 2014[19] evaluated the mechanical properties of jute, coir \& bamboo reinforced hybrid epoxy composites prepared differently by taking epoxy resin AW 106/ HV 953 hardener in the ratio (10:7.5) by weight. The tests resulted with maximum tensile and compressive strength for bagasse reinforced epoxy composite.

* N.Vijay Sai et al 2014[20] studied about the transverse vibration analysis of hybrid sisal-bagasse fabric reinforced epoxy composites. The main purpose of this paper was to determine the damping factor and mode shapes for a cantilevered rectangular symmetric plate of hybrid sisal-bagasse fabric reinforced epoxy composite with fiber orientation $\left(+90^{\circ} \%+45^{\circ} / 0^{\circ} /-45^{\circ} /-90^{\circ}\right)$ using a fast Fourier technique based spectrum analyzer. It was found that hybrid sisal bagasse epoxy composites comprises good damping factor when compared to traditional composites. Therefore these composites can be utilized as vibration absorbing materials in applications such as for construction roofing material, automobile industries and for indoor application.

* Xue Li et al 2007[21] reviewed certain research papers making use of chemical treatments of fibres and reviewed each of them in detail which also discussed that 5\% $\mathrm{NaOH}$ treatment is most suitable treatment as $10 \%$ treatment resulted in di-lignification of fibres causing weak or damaged fibre and how chemical treatment directly improves the properties of fibre by removing dust, dirt and waxes on fibre surface thereby increasing fibre- matrix adhesion.

* Vikas Sahu et al 2015[22] carried out work on sisal/pineapple reinforced epoxy hybrid composites in different fibre ratio as 100/0, 70/30, 50/50, 30/70, 0/100 respectively by weight. Hand layup method was used for composite preparation and samples were cut according to ASTM standards for testing. The tests depicted best impact strength of $47.32 \mathrm{~N} / \mathrm{mm}^{2}$ for $50 / 50$ composite and best tensile and flexural strength for 100/0 composite. In the same manner many other research papers were also studied which opened the way for the current research work and gave proper insight regarding its accomplishment.

\section{B. RESEARCH GAP}

After extensive literature survey, it was found that not much research has been undertaken for testing of mechanical properties and water absorbing behaviour of composite taking Sisal and Bagasse fibre in varying fibre ratios in hybrid epoxy composites.

Hence to fulfill this research gap, a new class of composite was developed using Sisal and Bagasse fibres reinforced in epoxy AW106/ HV 953 resin with varying fibre ratios in composites and alkali treatment was also performed to improve mechanical properties of the composite.

\section{OBJECTIVES}

The objectives of current research work are outlined below:

$>$ To functionalize the sisal and bagasse fiber by $\mathrm{NaOH}$ treatment and fabricate four different hybrid epoxy composites with three containing treated fibres and last one reinforced with untreated fibres by hand layup method.

$>$ To develop a new class of composites by developing four different hybrid epoxy composites coded as $\mathrm{C}_{1}$, $\mathrm{C}_{2}, \mathrm{C}_{3}, \mathrm{C}_{4}, \mathrm{C}_{5}$ with resin: sisal: bagasse ratio as:

- $\mathrm{C}_{1}$ (Neat Epoxy) 100:0:0

- $\mathrm{C}_{2}$ (Treated) 60:30:10

- $\mathrm{C}_{3}$ (Treated) 60:20:20

- $\mathrm{C}_{4}$ (Treated) 60:10:30

- $\mathrm{C}_{5}$ (Untreated) 60:20:20

$>$ To investigate the mechanical properties such as tensile strength, tensile modulus, flexural strength, flexural modulus, impact strength (Izod), hardness (Rockwell) and water absorption capacity of these hybrid composites according to ASTM standards.

Besides above all objectives, this research work is destined to develop a new type of composite which is expected to find many applications in future.

\section{FABRICATION AND TESTING}

This chapter deals with the materials required for preparation of composites, preparation of fibres for fabrication, method of fabrication of composites, sample preparation and their testing.

\section{A. MATERIAL REQUIREMENT}

The materials required for fabrication of composites are:

1. Natural fibres ( Reinforcement )

$>$ Sisal fibre

$>$ Sugarcane bagasse fibre

2. Polymer material ( Matrix )

$>$ Epoxy Resin ( AW 106)

$>$ Hardener ( HV 953 )

3. Alkali Treatment

$>$ Sodium Hydroxide $(\mathrm{NaOH})$

$>$ Dilute Hydrochloric acid $(\mathrm{HCl})$ 
a) SISAL FIBRE ( Agave sisalana )- The Sisal fibres used in this work have been supplied from Vrushka Composites, Tamil Nadu. Sisal fiber has high specific strength and modulus, easy availability, low price, reusability, etc. The Sisal plant has a life-span of 7-10 years and generally produces 200-250 commercially usable leaves and each one contains an average of around 1000 fibres[23]. The fibers obtained are dried in sun which whitens the fiber. After drying, the fibers are ready for knotting. Sisal fibres are being primarily used in high strength ropes, especially in South India.

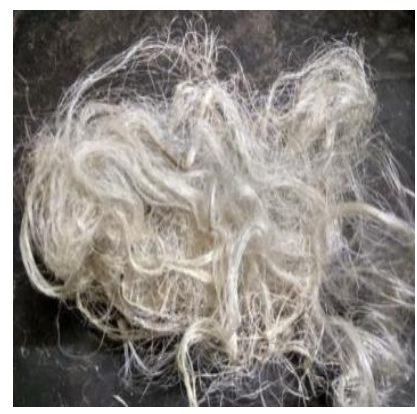

b) SUGARCANE BAGASSE FIBRE ( Saccharum officinarum ) - The Bagasse fibres utilized in this work were obtained from local market. Sugarcane bagasse is a plentiful lingo cellulosic waste typically found in countries that harvest sugarcane such as India, Cuba, Brazil and China. About 54 million tons of bagasse is produce annually throughout the world.

Bagasse which is left after the juice has been extracted from the sugar cane biodegrades in 25-65 days. Each 10 tons of sugarcanes processed in a sugar factory produces approximately 3 tons of wet bagasse. Bagasse is primarily employed as a burning raw material in the sugar cane mill furnaces. Approximately $9 \%$ of bagasse is employed in alcohol (ethanol) production.



c) EPOXY RESIN ( AW 106 )- The ARALDITE AW 106 epoxy resin manufactured by Huntsman America Inc. used in this work for fabrication of composites was obtained from local market. Epoxy resins have certain outstanding properties which makes them most widely used thermosetting polymer which are as follows:

a) Superior adhesion to different materials.

b) Exceptional strength and toughness.

c) Good chemical and moisture resistance.

d) Tasteless, Odorless and non-toxic. d) HARDENER ( HV 953 )- The ARALDITE HV 953 hardener manufactured by Huntsman America Inc. used in this work for curing of resin was obtained from local market. Curing is an exothermic process which improves the property of resin and hardener helps in curing reaction. It changes linear epoxy resin structure to $3 \mathrm{D}$ cross linked structure.

Epoxy Resin and Hardener



\section{B. ALKALI TREATMENT}

Alkali treatment or mercerization is most widely used procedure for chemical treatment of natural fibres. This treatment removes lignin, waxes, dirt and oil from fibre surface thereby improving its mechanical properties. Alkali treatment affects the fibre property in following ways:

1. It exposes surface of fibre much more towards resin by increasing surface roughness of fibre, thereby improving fibre-matrix adhesion.

2. It exposes the cellulose on surface of fibre hidden by oil and wax cover, thereby increasing the number of possible reaction sites.

In this research work, fibres were firstly washed in distilled water 2 to 3 times and then dried in sun for two consecutive days. Then, after drying they were dipped in $5 \%(\mathrm{w} / \mathrm{v}) \mathrm{NaOH}$ solution for 10 hours at $23^{\circ} \mathrm{C}$. After that fibres were removed from alkali solution and treated with dilute hydrochloric acid to remove excess of $\mathrm{NaOH}$. Then fibres were washed thoroughly in distilled water and then dried in sun for 48-50 hours.

\section{COMPOSITE FABRICATION}

The composites have been fabricated using traditional hand layup method. Firstly, mild steel mold of dimensions $200 \mathrm{~mm} * 200 \mathrm{~mm} * 5 \mathrm{~mm}$ was prepared and cleaned thoroughly with a brush to remove any dust or dirt. Then mold release spray was applied all over the mold to facilitate easy removal of composite from the mold after its curing.

Then treated and untreated fibres (both sisal and bagasse) along with epoxy resin and hardener were taken according to weight as desired in objectives of composite preparation.

Volume of Composite: $200 * 200 * 5 \mathrm{~mm}^{3}=200 \mathrm{~cm}^{3}$

Density of Matrix (Resin + Hardener $)=1.05 \mathrm{~g} / \mathrm{cm}^{3}$

Density of Sisal fibre $=1.35 \mathrm{~g} / \mathrm{cm}^{3}$

Density of Bagasse fibre $=1.25 \mathrm{~g} / \mathrm{cm}^{3}$

Weight of fibre $=$ Density of fibre $*$ Volume of fibre in composite 
Composition and Designation of Composites

\begin{tabular}{|c|c|c|c|}
\hline Sample code & $\begin{array}{c}\text { Resin: Sisal: } \\
\text { Bagasse } \\
\text { (Volume \%) }\end{array}$ & $\begin{array}{c}\mathrm{R}: \mathrm{S}: \mathrm{B} \text { volume } \\
\text { ratio } \\
\left(\text { in } \mathrm{cm}^{\mathbf{3}}\right)\end{array}$ & $\begin{array}{c}\text { R:S:B weight } \\
\text { ratio } \\
\text { (in grams) }\end{array}$ \\
\hline $\begin{array}{c}\mathrm{C}_{1} \\
\text { (Neat Epoxy) }\end{array}$ & 100:0:0 & 200:0:0 & 210:0:0 \\
\hline $\begin{array}{c}\mathrm{C}_{2} \\
\text { (Treated) }\end{array}$ & $60: 30: 10$ & $120: 60: 20$ & $126: 81: 25$ \\
\hline $\begin{array}{c}\mathrm{C}_{3} \\
\text { (Treated) }\end{array}$ & $60: 20: 20$ & $120: 40: 40$ & $126: 54: 50$ \\
\hline $\begin{array}{c}\mathrm{C}_{4} \\
\text { (Treated) }\end{array}$ & $60: 10: 30$ & $120: 20: 60$ & $126: 27: 75$ \\
\hline $\begin{array}{c}\mathrm{C}_{5} \\
\text { (Untreated) }\end{array}$ & $60: 20: 20$ & $120: 40: 40$ & $126: 54: 50$ \\
\hline
\end{tabular}

The epoxy resin and hardener were taken in amount calculated as above with resin: hardener ratio as 100:80 (by weight) according to the standards and stirred properly in a glass beaker for 2 to 3 minutes. The sides and bottom of the beaker is scraped properly with a spatula to leave no resin uncured. The resin and hardener is stirred slowly to avoid any formation of bubbles which might affect the properties of composite during fabrication.

Then a layer of mixture is applied on mold sheet and then sisal fibres(length $\sim 25 \mathrm{~cm}$ ) is laid carefully in the mold and another layer of mixture is applied on sisal fibres and pressed with rollers to remove the air entrapped between fibres and then short bagasse fibres (length $\sim 5-6 \mathrm{~mm}$ ) were scattered on mixture layer and pressed with rollers once again and then final layer of resin mixture is applied over bagasse fibres and finally the fabrication is covered with a mold sheet and pressed under a $50 \mathrm{~kg}$ load at room temperature for 24 hours. The composites were detached from the mold after 24 hours and specimens were cut according to ASTM standards.



Composite Fabrication

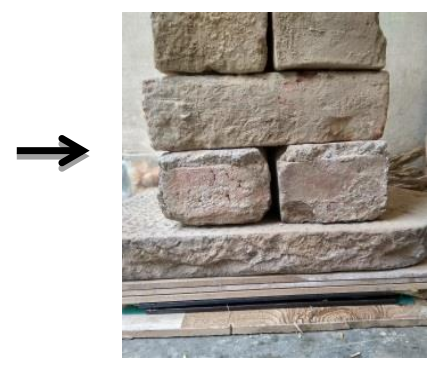

Pressed under heavy load

\section{SAMPLE CUTTING}

After all the composites were fabricated and taken out from the mold they were cleaned with a clean cloth to remove mold releasing agent, dust or dirt, etc. Then samples were cut out according to ASTM standards for testing. The dimensions of the samples are as follows:

a) Tensile Test Specimen (ASTM D638) - The specimen's dimensions are $150 \times 15 \times 6 \mathrm{~mm}^{3}$.

b) Flexural Test Specimen(ASTM D790)- The specimen's dimensions are $127 \times 13 \times 6 \mathrm{~mm}^{3}$.

c) Izod Impact Test Specimen(ASTM D256)- The specimen's dimensions are $63 \times 13 \times 6 \mathrm{~mm}^{3}$. d) Rockwell Hardness Test Specimen (ASTM D785) The specimen's dimensions are $50 \times 50 \times 6 \mathrm{~mm}^{3}$.

e) Water Absorption Test Specimen (ASTM D 570) The specimen's dimensions are $50 \times 50 \times 6 \mathrm{~mm}^{3}$.

\section{E. MECHANICAL TESTING}

After the samples were cut according to the standards, following tests which were carried out on them to find out the best composite material are:

a) Tensile test

b) Flexural test

c) Impact test (Izod)

d) Hardness test (Rockwell)

e) Water Absorption test

a) TENSILE TEST- This test is performed to find out the tensile strength of the composite. The specimen dimensions $\left(150 \times 15 \times 6 \mathrm{~mm}^{3}\right)$ in tensile test were according to ASTM D638 standards. In this test a constant uniaxial load is applied at both ends of the specimen until it breaks into two pieces. The test was carried by using INSTRON 3382 DUAL COLUMN FLOOR MODEL Universal Testing Machine as shown in figure below. The samples were strained at rate of $50 \mathrm{~mm} / \mathrm{min}$.
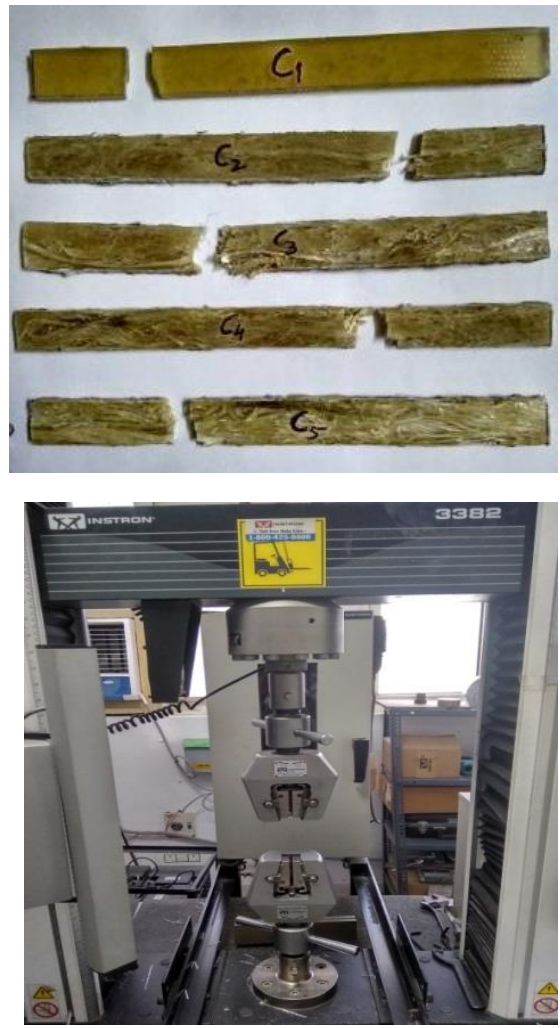

\section{Tensile Test Procedure}

FLEXURAL TEST- This test is performed to find out the flexural strength of the composite i.e. the strength which the material can absorb before breaking under bending load. The specimen to be tested is placed on the support span and force is applied perpendicularly at the centre of the specimen by the loading nose, thereby producing a 3-point bending at a 
specified rate. The specimen dimensions $\left(127 \times 13 \times 6 \mathrm{~mm}^{3}\right)$ in flexural test were according to ASTM D790 standards.

The tests were carried out using INSTRON 3382 UTM using flexural fixture and set up by engaging a span of $80 \mathrm{~mm}$ maintained at a cross head speed of $2 \mathrm{~mm} / \mathrm{min}$. The flexural strength is determined by the following formula:

$$
\mathrm{F}=3 \mathrm{PL} / \mathrm{bt}^{2} \text {, where } \mathrm{F}=\text { flexural strength of specimen, }
$$
$\mathrm{P}=$ load applied under bending

$$
\begin{aligned}
& \mathrm{L}=\text { gauge length } \\
& b=\text { width of specimen } \\
& t=\text { thickness of specimen }
\end{aligned}
$$

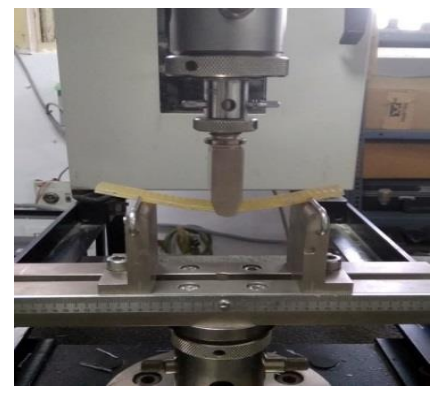

Flexural Test Procedure

b) IMPACT (IZOD) TEST- This test is performed to find out the impact strength of the composite i.e. toughness of the specimen. In this test a notched specimen is clamped in the anvil with the notch facing the swinging hammer.

The hammer is raised to a certain height and left instantaneously to hit the notched specimen and break it apart. The energy absorbed by the specimen before breaking in two pieces due to impact is called impact strength of the specimen.

This test is also used to test the notch sensitivity of the specimen. The test was carried out on TINIUS OLSEN IT504 as shown in Fig. below. The specimen dimensions $\left(63 \times 13 \times 6 \mathrm{~mm}^{3}\right)$ in impact test were according to ASTM D 256 standards.


Notched Specimen $\mathrm{C}_{1}$

Izod Impact Testing Procedure

\section{c) ROCKWELL HARDNESS TEST}

This test is performed to find out the hardness of the composite material i.e. the capacity of the material to resist penetration or indentation on its surface. The harder the material, larger will be the reading.
The tests were carried out using Rockwell Hardness Testing Machine as shown in Figure below. The maximum working range of the machine is $150 \mathrm{~kg}$. The specimen dimensions $\left(50 \times 50 \times 6 \mathrm{~mm}^{3}\right)$ were according to ASTM D785 standards. The difference between the readings of the dial under major load and under the preload gives the hardness of the specimen.

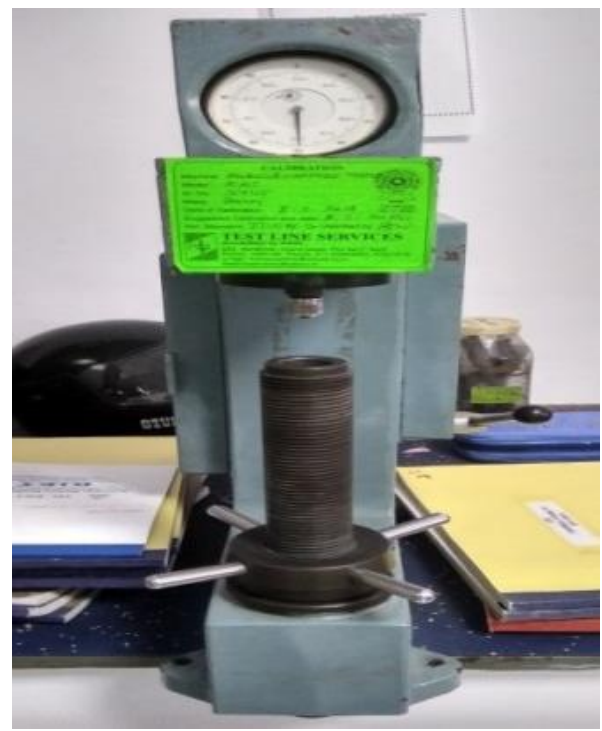

\section{Rockwell Hardness Testing Procedure}

d) WATER ABSORPTION TEST- This test is performed to determine the water absorbing capacity of the composite. The specimen dimensions $\left(50 \times 50 \times 6 \mathrm{~mm}^{3}\right)$ were according to ASTM D570 standard.

Firstly the samples were dried thoroughly in the sun for 10-12 hours to remove moisture, if any. Then they were weighed immediately up to 3 places of decimals. After weighing the samples were dipped in distilled water at room temperature $\left(\sim 23^{\circ} \mathrm{C}\right)$ for 24 hours. Samples were taken out after 24 hours, dried and weighed again and readings were carefully noted. Weighing Machine used for weighing the samples is shown below.

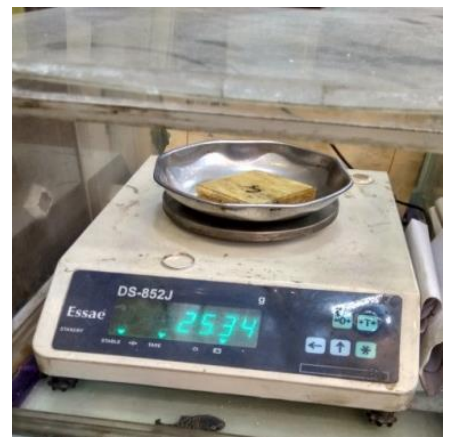

Weighing of Sample $\mathrm{C}_{5}$

\section{EXPERIMENTAL ANALYSIS}

\section{A. ANALYSIS OF TENSILE STRENGTH OF SAMPLES}

After performing tensile test for all five specimens on INSTRON 3382 UTM, the data has been clearly and accurately analyzed through graph for variation in tensile strength. The graph given below clearly shows the variation in tensile strength of the samples. 


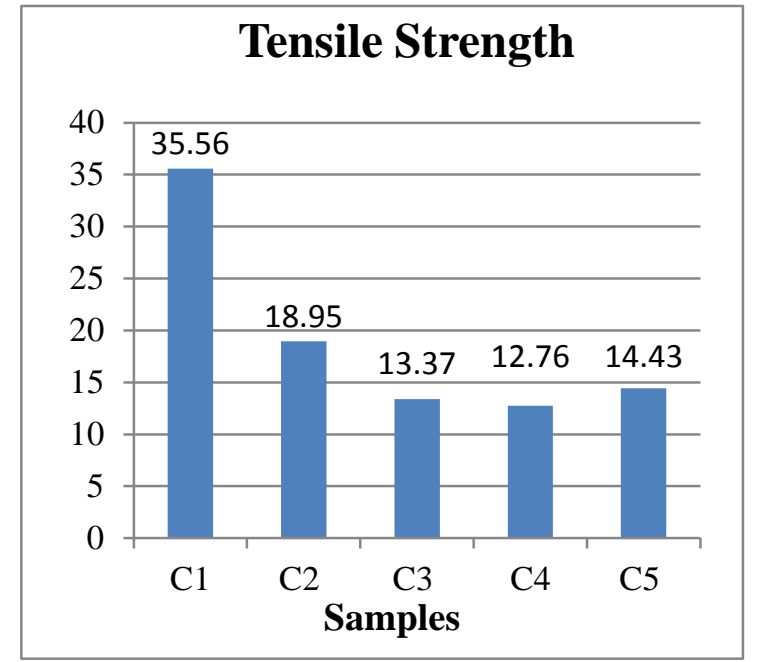

Variation of Tensile strength of Samples

From the analysis made by graph it is clearly evident that Sample $C_{1}$ (Neat Epoxy) with R: S: B ratio as 100:0:0 has maximum tensile strength- $35.56 \mathrm{MPa}$.

\section{B. ANALYSIS OF TENSILE MODULUS OF SAMPLES}

Tensile Modulus also referred to as Young's Modulus defines the relationship between stress and strain characteristics of the sample. The slope of the stress strain curve gives the tensile modulus of the samples. The graph given below gives a proper analysis of variation of tensile modulus of samples.



Variation of Tensile Modulus of Samples

From the analysis mage by Graph it is clearly evident that Sample $C_{5}$ (Untreated) with $R$ : $S$ : $B$ ratio as 60:20:20 has maximum tensile modulus i.e. 806.35 Mpa.

C. ANALYSIS OF FLEXURAL STRENGTH OF SAMPLES

After performing flexural test for all specimens on INSTRON 3382 UTM, the collected data has been clearly represented in the graph given below which clearly illustrates the variation of flexural strength of the samples.

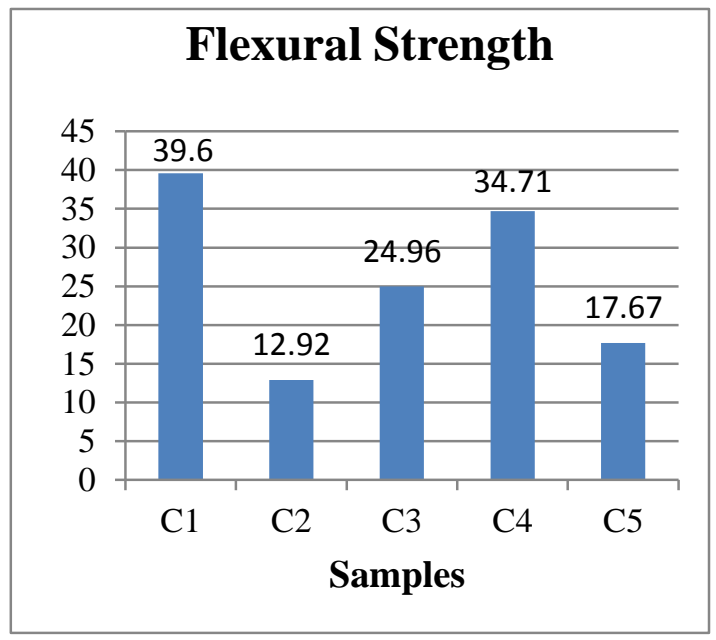

Variation of Flexural Strength of Samples

From the analysis made by graph it is clearly evident that Sample $\mathbf{C}_{\mathbf{1}}$ (Neat Epoxy) with R: S: B ratio as 100:0:0 has maximum flexural strength i.e. 39.6 Mpa.

\section{ANALYSIS OF FLEXURAL MODULUS OF SAMPLES}

Flexural modulus also referred to as bending modulus is defined as the ratio of flexural stress to flexural strain, or the tendency of the material to resist bending. The graph analyses the data to determine the variation of flexural modulus of specimens.



Variation of Flexural Modulus of Samples

The analysis made from graph clearly shows that Sample $C_{5}$ (Untreated) with $\mathbf{R}$ : $\mathbf{S}$ : $\mathbf{B}$ ratio as 60:20:20 has maximum flexural modulus i.e. 1720.79 Mpa.

\section{E. ANALYSIS OF (IZOD) IMPACT STRENGTH OF SAMPLES}

After performing Impact test (Izod) for all samples on TINIUS OLSEN, the data for impact strength has been collected accurately and graph given below shows the variation of impact strength of samples. 


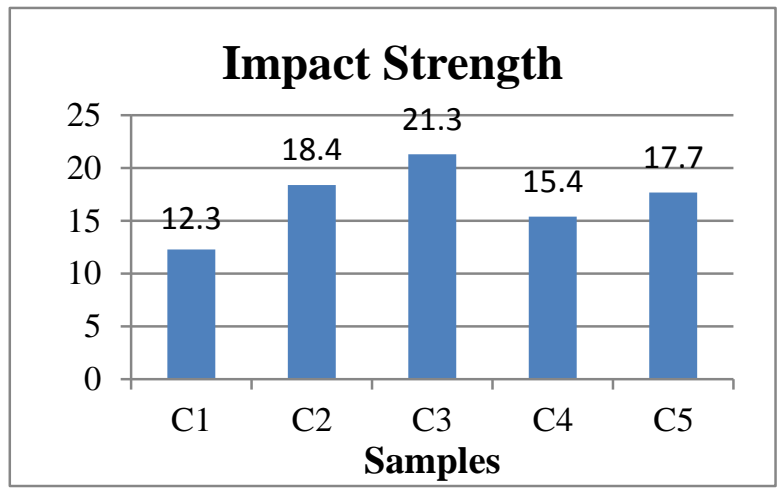

Variation of Impact Strength of Samples

From the analysis of the graph it is clearly evident that Sample $C_{3}$ (Treated) with $R$ : $S$ : $B$ ratio as 60:20:20 has maximum Impact Strength i.e. $21.3 \mathbf{~ k J} / \mathbf{m}^{2}$.

\section{F. ANALYSIS OF (ROCKWELL) HARDNESS OF SAMPLES}

After performing Rockwell hardness test on Hardness Testing Machine for all samples the data collected is represented clearly in the graph and also analyzed by the help of graph as represented below.



Variation of Hardness of Samples

From the analysis made by graph it is clearly evident that Sample $C_{2}$ (Treated) with $R: S: B$ as 60:30:10 has maximum hardness i.e. 137.

\section{G. ANALYSIS OF WATER ABSORPTION BEHAVIOUR OF SAMPLES}

After performing water absorption test on all five samples accurately, the data regarding the test is clearly depicted in table below and based on that table variation of water absorption $\%$ is analyzed.

Experimental Data for Water Absorption Test

\begin{tabular}{ccccc}
\hline S.No. & Samples & $\begin{array}{c}\text { Weight at } \\
\text { time t }=\mathbf{0} \\
\text { hrs. }, \mathbf{w}_{\mathbf{0}} \\
\text { (grams) }\end{array}$ & $\begin{array}{c}\text { Weight at } \\
\text { time t= 24 } \\
\text { hrs. , } \mathbf{w}_{\mathbf{t}} \\
\text { (grams) }\end{array}$ & $\begin{array}{c}\text { Percentage } \\
\text { change in } \\
\text { weight }(\boldsymbol{\%})\end{array}$ \\
\hline $\mathbf{1}$ & $\mathrm{C}_{1}$ & 17.990 & 23.124 & 28.54 \\
$\mathbf{2}$ & $\mathrm{C}_{2}$ & 18.320 & 24.980 & 36.35 \\
$\mathbf{3}$ & $\mathrm{C}_{3}$ & 19.370 & 26.839 & 38.56 \\
$\mathbf{4}$ & $\mathrm{C}_{4}$ & 19.880 & 28.659 & 44.16 \\
$\mathbf{5}$ & $\mathrm{C}_{5}$ & 18.080 & 25.340 & 40.15 \\
\hline
\end{tabular}

From the analysis made by graph it is clear that Sample $C_{1}$ (Neat Epoxy) with $R$ : $S$ : $B$ ratio as 100:0:0 has the least water absorption \% of all the samples i.e. $\mathbf{2 8 . 5 4}$ $\%$.

\section{RESULTS AND DISCUSSIONS}

The following conclusions have been drawn out from the results:

- As the Sisal content goes on increasing in Sisal/Bagasse hybrid composite Tensile Strength, Tensile Modulus, Rockwell hardness increases whereas Flexural Strength, Flexural Modulus, Water Absorption\% decreases.

- As the Bagasse content goes on increasing in Sisal/Bagasse hybrid composite Flexural Strength, Flexural Modulus, Water Absorption\% increases whereas Tensile Strength, Tensile Modulus, Rockwell Hardness decreases.

- Impact Strength shows a moderate variation as it increases upon addition of fibres but as soon as bagasse contents reaches $\mathbf{3 0 \%}$ in the composite it decreases as increased bagasse content creates voids and thus leads to poor fibre- matrix adhesion.

- Sample $\mathbf{C}_{1}$ (Neat Epoxy) has maximum tensile strength i.e. 35.56 MPa.

- Tensile and Flexural Modulus of $\mathbf{C}_{5}$ increased by $\mathbf{1 8 . 7 9 \%}$ and $\mathbf{5 4 . 8 9 \%}$ upon reinforcement of Sisal/Bagasse in the ratio 20/20 into neat epoxy.

- Izod Impact Strength of $\mathbf{C}_{\mathbf{3}}$ enhanced by $\mathbf{7 3 . 1 7 \%}$ after reinforcement of Sisal/Bagasse in the ratio of $\mathbf{2 0 / 2 0}$ into neat epoxy.

- Rockwell hardness of $\mathrm{C}_{2}$ enhanced by $\mathbf{4 5 . 7 4 \%}$ after reinforcement of Sisal/Bagasse in the ratio $\mathbf{3 0 / 1 0}$ into neat epoxy.

- Sample $\mathbf{C}_{1}$ (neat epoxy) has maximum flexural strength i.e. 39.60 MPa and least Water absorption due to absence of fibres.

Comparison of properties of Treated and Untreated Samples having same composition

\begin{tabular}{cccc}
\hline Properties & $\mathbf{C}_{\mathbf{3}}$ (Treated) & $\mathbf{C}_{\mathbf{5}}$ (Untreated) & \% Change \\
\hline $\begin{array}{c}\text { Tensile } \\
\text { Strength }\end{array}$ & 13.37 & 14.43 & $\begin{array}{c}7.35 \% \\
(\text { decrease) }\end{array}$ \\
$\begin{array}{c}\text { Tensile } \\
\text { Modulus }\end{array}$ & 605.94 & 806.35 & $\begin{array}{c}24.85 \% \\
\text { (decrease) }\end{array}$ \\
$\begin{array}{c}\text { Flexural } \\
\text { Strength }\end{array}$ & 24.96 & 17.67 & $\begin{array}{c}41.25 \% \\
\text { (increase) }\end{array}$ \\
$\begin{array}{c}\text { Flexural } \\
\text { Modulus }\end{array}$ & 1120.51 & 1720.79 & $\begin{array}{c}34.88 \% \\
\text { (decrease) }\end{array}$ \\
$\begin{array}{c}\text { Impact } \\
\text { Strength }\end{array}$ & 21.3 & 17.7 & $\begin{array}{c}20.34 \% \\
\text { (increase) }\end{array}$ \\
$\begin{array}{c}\text { Rockwell } \\
\text { Hardness }\end{array}$ & 121 & $15.24 \%$ \\
Water & 38.56 & 40.15 & $\begin{array}{c}1.59 \% \\
\text { (increase) }\end{array}$ \\
Absorption $(\%)$ & (decrease) \\
\hline
\end{tabular}

From the above analysis it is clear that, alkali treatment has brought a considerable change in the properties of composites having same composition $(60: 20: 20)$ which is discussed below:

1) Tensile Strength and Tensile Modulus have slightly decreased after alkali treatment due to decrease in cellulose content of fibre after prolonged exposure to alkaline environment. Cellulose is primarily responsible for tensile strength of fibres.

2) Flexural Strength, Impact Strength and Rockwell hardness have increased considerably after alkali treatment due to increase in surface adhesion between fibre and matrix. Water Absorption\% has decreased 
after alkali treatment due to decrease in pectin and cellulose content which are primarily responsible for hydrophilicity.

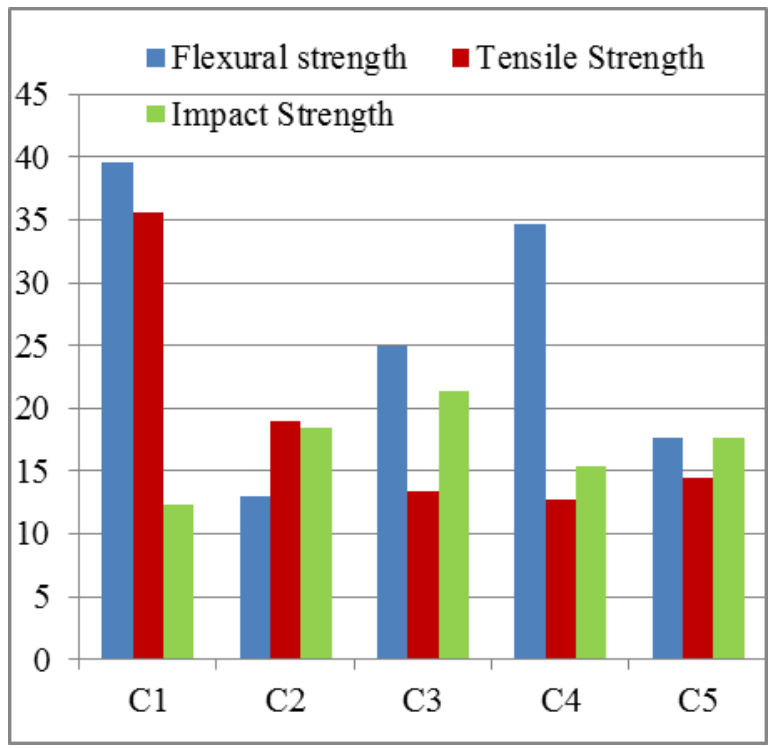

Comparison of Mechanical properties of all Samples

\section{A. FUTURE SCOPE}

There is a wide scope for future researchers and scholar to explore further in the current research work. This work can be further expanded to wide aspects of composites field in some of the ways mentioned below:

$>$ Usage of some other natural fibres and testing their mechanical behavior by utilizing the same parameters employed in this research work.

$>$ Investigation of properties other than mechanical such as chemical, electrical, physical, thermal or tribological properties using the same fibres and same parameters as used in this work.

\section{REFERENCES}

[1]. Jones, R.M. (1999). Mechanics of Composite Materials, Taylor and Francis Inc., pp.31-33.

[2]. Berghezan, A,(1966), "Non-ferrous Materials," Nucleus, pp, 5-11

[3]. Van Suchtelen,(1972), "Product Properties: a new application of composite materials, Philips Res. Reports, Vol.27, pp. 28.

[4]. Jurtiz, A.E., (1965), "Design," pp.18.

[5]. Kelly, A., (1967), Sci.American,217, (B), pp. 161.

[6]. Gurdal, Z., Haftka, R.T. , \& Hajela, P. (1999). Design and Optimization of Laminated Composite Materials, pp.6-7.

[7]. Chandra Mohan D., and Marimuthu, K., (2011). A Review On Natural Fibres, International Journal of Recemt Research and Applied Studies, Vol.8, Issue 2.

[8]. Sangamesh Reddy \& Sunil J. Mangshetty (2016).Synthesis and Characterization of Sisal \& Hemp Fiber Reinforced Hybrid Composites, International Journal for Scientfic Research \& Development, Issue 07,pp: 2321-0613.

[9]. K.V. Sreenivas Rao, N.S. Venkatesha Gupta(2016). Mechanical Properties of Natural Fibers Reinforces Hybrid Composites. ARPN Journal of Engineering and Applied Sciences, ISSN 1819-6608.

[10]. P.C. Gope, V.K. Singh, Maneesh Tewari, Arun K. Chaudhary(2011). Evaluation of Mechanical Properties of Bagasse- Glass Fibre Reinforced Composite, Journal of Materials and Environmental $\begin{array}{llll}\text { Science, } & \text { ISSN: } & 2028- & \end{array}$ https://www.researchgate.net/publication/256941412.

[11]. R. Prasanna Venkatesh, K. Ramanathan, V. Srinivasa Raman (2015). Tensile, Flexural, Impact and Water Absorption Properties of Natural
Fibre Reinforced Polyester Hybrid Composites, Fibers \& Textiles in Eastern Europe 2016, Vol. 24, 3(117): 90-94.

[12]. DS Kumar, N Abhishek, P Vandana, BC Ray (2017). Fabrication and Testing of Mechanical Properties of Bagasse Natural Fiber Composite, International Journal of Current Engineering and Scientific Research. ISSN (PRINT): 2393-8374, (ONLINE): 2394-0697, Volume-4, Issue-7, 2017.

[13]. Jai InderPreet Singh, Dr. Vikas Dhawan, Amrinder Singh Pannu (2017). Effect of Alkali Treatment on Mechanical properties of Jute, Sisal, Banana, Hemp and Abaca fibers for Polymer Composite Reinforcement, International journal of Mechanical Engineering and Technology (IJMET), Volume 8, Issue 7,July 2017, pp:1775-1784.

[14]. Abdul Nazeer (2014). To study the mechanical p[roperties of coconut coir fiber reinforced with epoxy resin AW 106 \& HV 953IN. International Journal of Modern Engineering Research(IJMER), Vol. 4, Issue 7, ISSN: 2249-6645.

[15]. RG Padmanabhan, M. Ganapathy (2015). Investigation of Mechanical Behavior of Bagasse (Sugarcane)- Alovera as Hybrid Natural Fibre Composites, International Journal for Research in Applied Science \& Engineering technology, Volume 3, Issue X, ISSN: 2321-9653.

[16]. Anurag Thawait (2016). Investigation of Mechanical Properties and Application Possibilities of Musa Acuminata fibre Reinforced Composite, International journal of Engineering Science and Computing, Volume 6, Issue 5, ISSN: 2321-3361.

[17]. M. Sudhagar, Arunkaarthick. V(2016). Hybrid Composite based on Sisal, Flax \& Glass fiber, International Journal of Recent Trends in Engineering \& Research(IJRTER),Volume 02, Issue X, ISSN: 2455-1457.

[18]. P. Sudhir Kumar \& T. Naresh Kumar(2017), Fabrication and Testing of Composite Powder Materials from Tamarind Seeds and Palm Date Seeds using Epoxy, International Journal of Research, Volume 04, Issue14, ISSN: 2348-6848.

[19]. Amit Kumar Tanwer(2014), Effect of Mechanical Properties for Jute, Coir and Bamboo Natural Fiber Reinforced Epoxy based Composites, American International Journal of Research in Science, Technology, Engineering \& Mathematics, AIRJSTEM 14-17, ISSN (Print): 2328-3491

[20]. N. Vijaya Sai, P. Nanda Kishore(2014), Investigation on Dynamic Behaviour of Hybrid SISAL/BAGASS Fiber Reinforced Epoxy Composites, International Journal of Innovative Research in Advanced Engineering (IRIJRAE), Volume $1, \quad$ Issue 6 ISSN:2349-2163.

[21]. Xue Li, Lope G. Tabil \& Satyanarayan Panigarhi(2007), Chemical Treatments of Natural Fiber for Use in Natural fiber Reinforced Composites: A Review, Journal of Polymers and Environment, https://www.researchgate,net/publication/225613743

[22]. Vikas Sahu, Keshav Singh Bisen \& Murali Krishna(2015), International Journal of Modern Engineering research(IJMER), Vol. 5, Issue 1, ISSN: 2249-6645.

[23]. Ramesh, M., Palanikumar, K. and Reddy, K.H. (2013) Mechanical Property Evaluation of Sisal-Jute-Glass Fiber Reinforced Polyester Composites. Composites: Part B,48,1-9. http://dx.doi.org/10.1016/j.compositesb.2012.12.004 